\title{
Effect of linolenate on photosynthesis by intact spinach chloroplasts $I$. \\ Inhibition of orthophosphate uptake and of 3-P-glyceraldehyde efflux across the chloroplast envelope
}

\author{
Paul-André Siegenthaler and Lambert Mvé Akamba ${ }^{1}$
}

Laboratoire de Physiologie végétale et Biochimie, Université de Neuchâtel, 20, rue de Chantemerle, 2000 Neuchâtel, Switzerland

\begin{abstract}
Linolenic acid $\left(\mathrm{C}_{18: 3}\right)$ inhibited photosynthesis by intact spinach chloroplasts. This inhibition was due neither to a lack of NADPH in chloroplasts nor to a direct inhibition of the enzyme activities in the Calvin-Benson cycle. Linolenate inhibited $\mathrm{CO}_{2}$ fixation and oxygen evolution more effectively than $\mathrm{NADP}^{+}$photoreduction but did not inhibit the activity of several key enzymes of the Calvin cycle. Linolenate inhibited phosphate influx and 3-phosphoglyceraldehyde efflux across the chloroplast envelope. A hypothesis explaining the inhibition of photosynthesis by linolenate is presented.

Key words: Chloroplasts - Linolenic acid treatment - 3-P-glyceraldehyde efflux Phosphate uptake - Photosynthesis - Spinach - Transport.
\end{abstract}

The release of fatty acids during aging processes in vitro has been demonstrated in several cells and organelles such as human erythrocytes (30), mitochondria (10) and chloroplasts $(8,16,22,39,41)$. In chloroplasts, the main fatty acids released in the course of aging are $\mathrm{C}_{18}$-unsaturated fatty acids $(8,16,39)$, particularly linolenic acid; these acids are the most abundant in the thylakoid $(8,39)$ and envelope $(21)$ membrane lipids. So far, the action of endogenous $(31,38,39)$ and exogenous $(26$, $35-38$ ) fatty acids has been mainly studied in relation to the photochemical reactions of the thylakoid. It has been shown that such unsaturated fatty acids inhibit electron flow in photosystems II and I and the associated photophosphorylation (35, 37), light-induced shrinkage in chloroplasts (35), and the light-generated $\Delta \mathrm{pH}$ across thyalkoid membranes in a sequential fashion (37). In addition, fatty acids modify the physicochemical properties of the thylakoid membrane in such a way that swelling occurs $(27,34)$ and that the $\Delta \mathrm{pH}$ is diminished and $\mathrm{pHi}$ increased, inducing a shift of the $\mathrm{pH}$ optimum of electron flow towards acidity (37-39).

In order to elucidate further the control of photosynthetic activities by these fatty acids, we have now studied the action of linolenate on the photosynthetic apparatus at a higher level of structural integrity. The initial point of interest was: Would free fatty acids influence photosynthetic carbon metabolism in intact chloro-

1 This work is part of a doctoral program which is carried out by L. Mvé Akamba in this laboratory. 
plasts? Using short chain fatty acids, such as lipoic acid, octanoic acid and methyl octanoate, Pedersen et al. (20) have shown with Chlorella pyrenoidosa that these acids inhibit photosynthesis by blocking the carboxylation and bisphosphatase reactions and by decreasing the level of ATP. However, fatty acids paradoxically had no effect on ribulose 1,5-bisphosphate-carboxylase. These authors used fatty acids (300-600 $\mu \mathrm{M})$ which are not representative in chloroplast membrane lipids. At these concentrations, linolenate was shown to inhibit completely all photochemical reactions $(26,35-39)$.

In view of this, we have investigated the action of linolenic acid on photosynthesis in intact chloroplasts. Our results indicate that linolenic acid inhibits lightdependent oxygen evolution by impairing the exchange of metabolites across the chloroplast envelope. Part of this work has been presented recently (25).

\section{Materials and methods}

Intact chloroplasts from spinach (Spinacia oleracea var. Nobel) were isolated according to Kalberer et al. (17) in an isolation medium consisting of $25 \mathrm{~mm} \mathrm{~N}-2$ hydroxyethylpiperazine- $N^{\prime}$-2-ethanesulfonic acid (HEPES) adjusted to $\mathrm{pH} 7.6$ with $\mathrm{NaOH}, 330 \mathrm{~mm}$ sorbitol, $2 \mathrm{~mm}$ EDTA-Na ( $\mathrm{pH} 7.6)$ and $0.2 \mathrm{~mm}$ Na-isoascorbate. Rinsed leaves were placed on distilled water and preilluminated for about $60 \mathrm{~min}$ at $4^{\circ} \mathrm{C}$ with a tungsten $150 \mathrm{w}$ lamp (approx. $2300 \mathrm{lux}$ ). About $80 \mathrm{~g}$ of leaves, with midribs removed, were then homogenized in a Waring blender for about $5 \mathrm{sec}$ with $100 \mathrm{ml}$ of the isolation medium and filtered through 8 layers of cheesecloth. The filtrate was immediately centrifuged at $2500 \times \mathrm{g}$ for $10 \mathrm{sec}$ (excluding acceleration and braking time, using Sorvall RC $2 B$ and rotor SS-34). The supernatant was poured off, and the pellet was resuspended in the same medium. All operations were carried out at $4^{\circ} \mathrm{C}$. The chlorophyll content was determined by the method of Bruinsma (3). The chloroplast suspension, adjusted to $1.5 \mathrm{mg}$ chlorophyll per $\mathrm{ml}$, was kept at $0-4^{\circ} \mathrm{C}$ until use. The suspension contained about $70-80 \%$ of intact chloroplasts (13).

Photosynthetic oxygen evolution was measured with a Clark type oxygen electrode at $20^{\circ} \mathrm{C}$ in a $5 \mathrm{ml}$ cuvette containing the following reaction mixture: $350 \mathrm{~mm}$ sorbitol, $50 \mathrm{~mm}$ HEPES- $\mathrm{NaOH}(\mathrm{pH} 7.6), 0.2 \mathrm{~mm} \mathrm{Na}$-isoascorbate, $6.6 \mathrm{~mm} \mathrm{KHCO}_{3}$, chloroplasts usually at $100 \mu \mathrm{g}$ chlorophyll $/ \mathrm{ml}$ and, where indicated, Na-pyrophosphate ( $\mathrm{pH}$ 7.6), $\mathrm{K}$-phosphate ( $\mathrm{pH}$ 7.6) and linolenic acid dissolved in ethanol. All reaction mixtures contained less than $0.4 \%$ ethanol. The reaction was initiated by white light at an intensity of about $5 \times 10^{6} \mathrm{ergs} \cdot \mathrm{cm}^{-2} \cdot \mathrm{sec}^{-1}$ and monitored with a recorder.

$\mathrm{CO}_{2}$ fixation was assayed in $5 \mathrm{ml}$ flasks containing $1.5 \mathrm{ml}$ of the same reaction mixture as that for $\mathrm{O}_{2}$ evolution. The vessels were flushed with $\mathrm{N}_{2}$ for $4 \mathrm{~min}$ and then mounted on an agitator which imparted a swirling motion to the chloroplast suspension. The reaction mixture was preilluminated at about $10^{6} \mathrm{ergs}^{\cdot} \mathrm{cm}^{-2} \cdot \mathrm{sec}^{-1}$ for $5 \mathrm{~min}$ before the addition of $6 \mathrm{~mm} \mathrm{NaH}{ }^{14} \mathrm{CO}_{3}$ (specific radioactivity $0.1 \mu \mathrm{Ci}$ / $\mu$ mole). After $6 \mathrm{~min}$ illumination, $0.1 \mathrm{ml} 2 \mathrm{~N} \mathrm{HCl}$ was added and the mixture was centrifuged. Aliquots of the supernatant were dried on glass wool fiber $(9)$ and counted in a Chicago Scintillation counter.

The initial rate of electron transport from $\mathrm{H}_{2} \mathrm{O}$ to $\mathrm{NADP}^{+}$was measured spectro- 
photometrically in $0.2 \mathrm{~mm}(0.5 \mathrm{ml})$ cuvettes by recording the absorbance change at $340 \mathrm{~nm}$ in a Zeiss spectrophotometer, modified as described earlier $(24,36)$. The actinic light (1000 w iodine lamp) was passed through two interference filters (Balzer's Calflex $\mathrm{C}$ and Balzer's wide band DT-red) and the intensity at the cuvette was $1.15 \times 10^{4} \mathrm{ergs} \cdot \mathrm{cm}^{-2} \cdot \mathrm{sec}^{-1}$. The reaction mixture contained $50 \mathrm{~mm}$ Tricine (pH 8.4) $35 \mathrm{~mm} \mathrm{NaCl}, 5 \mathrm{~mm} \mathrm{MgCl} 2,0.5 \mathrm{~mm} \mathrm{~K}_{2} \mathrm{HPO}_{4}, 2 \mathrm{~mm}$ ADP, $2 \mathrm{~mm} \mathrm{NADP}$, ferredoxin in excess, intact chloroplasts $(100 \mu \mathrm{g}$ chlorophyll $/ \mathrm{ml})$ which were broken in this hypotonic medium, and linolenic acid at various concentrations. Ferredoxin was prepared from spinach leaves according to Buchanan and Arnon (4).

The uptake of orthophosphate ( $\mathrm{Pi}$ ) by intact chloroplasts (from non-preilluminated leaves) was assayed in a $3 \mathrm{ml} \mathrm{O} \mathrm{O}_{2}$ electrode cuvette containing the same reaction mixture as for $\mathrm{O}_{2}$ evolution, except that pyrophosphate (PPi) and sorbitol were replaced by $0.7 \mathrm{~mm} \mathrm{Pi}$, and $350 \mathrm{~mm}$ sucrose, respectively. Other conditions were identical to those used for the assay of $\mathrm{O}_{2}$ evolution. At the beginning and end of the light-reaction $(10 \mathrm{~min})$, aliquots of the chloroplast suspension were centrifuged and the $\mathrm{Pi}$ concentrations in the supernatants were estimated according to Fiske and Subbarow (11).

For the pyrophosphatase assay, a crude enzyme extract was prepared according to Schwenn et al. (32) and dialyzed against $50 \mathrm{~mm}$ Tris- $\mathrm{HCl}$ and $1 \mathrm{~mm} \mathrm{MgCl}_{2}$ at pH 8.0. The extract was kept frozen. Pyrophosphatase was assayed as described earlier (32) and Pi estimated according to Chen et al. (6). Ribulose 5-P-isomerase, ribulose 5-P-kinase and ribulose 1,5-bisP-carboxylase were tested according to Losada et al. (20); 3-phosphoglycerate-kinase and glyceraldehyde 3-P-dehydrogenase were also tested $(20)$. The activity of phosphotriose-isomerase was measured according to Kelly and Gibbs $(18)$.

The efflux of glyceraldehyde 3-phosphate (GAP) was assayed using the shuttle system 3-PGA/GAP as described by Kelly and Gibbs (19). The reaction mixture (described in the legend to Fig. 4) contained exogenous 3-PGA which penetrated the intact chloroplast (40) and then was reduced to GAP in the stroma. The resulting GAP left the chloroplast and was oxidized to 3-PGA outside the chloroplast by the addition of NADP+ and non-reversible D-glyceraldehyde-3-phosphate dehydrogenase (NR-GAPDH). The enzyme was isolated from the cyotledons of pumpkin grown in the dark according to Kelly and Gibbs (18). The assay was carried out in the oxygen electrode chamber for $14 \mathrm{~min}$, so that $\mathrm{O}_{2}$ evolution in the light could be followed. After $14 \mathrm{~min}$ the reaction mixture was centrifuged. The absorbance at $340 \mathrm{~nm}$ of the supernatant was determined and the dark "zero time" value was deducted. The amount of NADPH formed corresponded to the efflux of GAP.

Linolenic acid was obtained from Fluka (Switzerland).

\section{Results}

The effect of concentrations of linolenic acid on bicarbonate-dependent oxygen evolution by intact chloroplasts in the presence of optimal PPi can be seen in Fig. 1 . For the three chlorophyll concentrations used the control rates $(100 \%)$ were the same on the basis of chlorophyll. The inhibition of $\mathrm{CO}_{2}$-dependent $\mathrm{O}_{2}$ evolution by linolenic acid was more effective when a lower concentration of chlorophyll was used. If the chlorophyll concentration was plotted as a function of linolenic acid 


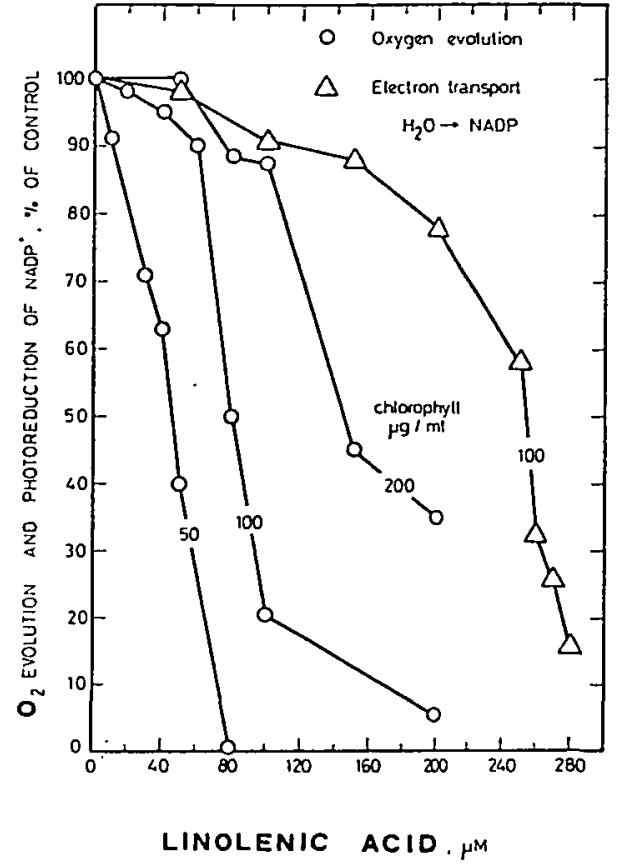

Fig. 1.

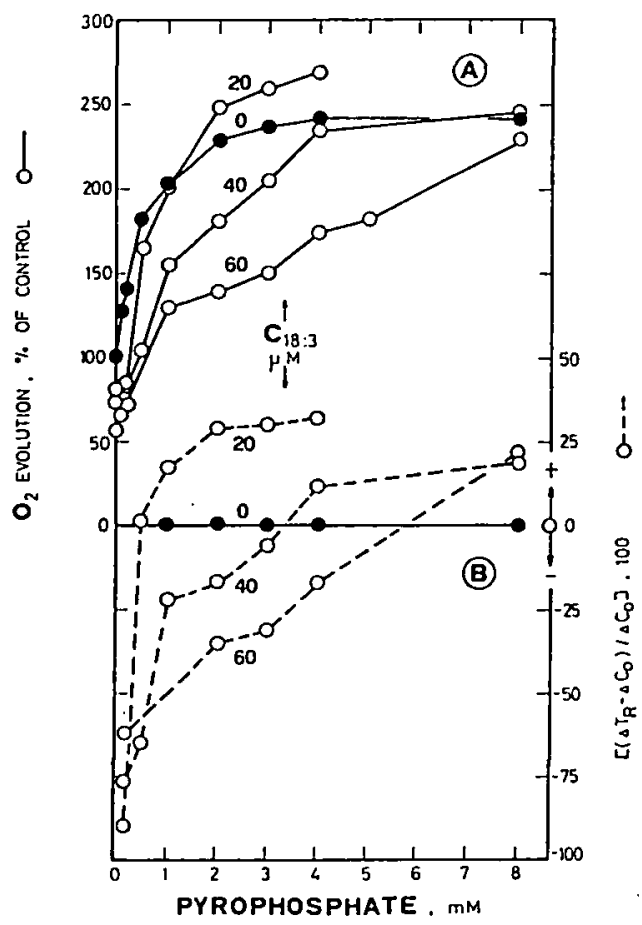

Fig. 2.

Fig. 1. Effect of linolenic acid on oxygen evolution and eletcron transport at different chlorophyll concentrations. $\mathrm{O}_{2}$ evolution and photoreduction of NADP+ were estimated in intact and broken chloroplasts, respectively. Numbers in the figure refer to chlorophyll concentrations $(\mu \mathrm{g} / \mathrm{ml})$. The control rates $(100 \%)$ were 30-60 $\mu$ moles $\mathrm{O}_{2}$ evolved $\cdot \mathrm{mg} \mathrm{chl}^{-1} \cdot \mathrm{hr}^{-1}$ and $155 \mu$ moles $\mathrm{NADPH}$ formed $\cdot \mathrm{mg} \mathrm{chl}^{-1} \cdot \mathrm{hr}^{-1}$. The reaction mixture for $\mathrm{O}_{2}$ evolution contained $4 \mathrm{mM} \mathrm{Na}{ }_{4} \mathrm{P}_{2} \mathrm{O}_{7} \cdot 10 \mathrm{H}_{2} \mathrm{O}(\mathrm{pH} 7.6)$; other conditions as described in Materials and methods.

Fig. 2. Pyrophosphate dependence of $\mathrm{O}_{2}$ evolution by intact chloroplasts in the absence and presence of linolenic acid. $\mathrm{O}_{2}$ evolution was expressed in (A) as \% of control (in the absence of linolenic acid, pyrophosphate and phosphate, $100 \%$ corresponded to $10-17 \mu$ moles $\mathrm{O}_{2}$ evolved $\cdot \mathrm{mg} \mathrm{chl}^{-1} \cdot \mathrm{hr}^{-1}$ ) and in (B) as [ $\Delta$ treated $\Delta$ control) $/ \Delta$ control] $\cdot 100$ (where $\Delta$ refers to the change in activity due to PPi). Other conditions as described in Materials and methods.

concentration, straight lines were obtained for each level of inhibition over most of the range. This indicates that up to $200 \mu \mathrm{g}$ chlorophyll/ml, identical molar ratios of $\mathrm{C}_{18: 3}$ /chlorophyll inhibit oxygen evolution to a similar extent. Half inhibition occurred at a molar ratio of 0.7 . This value was much lower than that for the inhibition of physiological electron flow in thylakoids (35-37). The experiments in Fig. 1 were therefore designed to compare oxygen evolution and electron flow from $\mathrm{H}_{2} \mathrm{O}$ to NADP+ using the same chloroplast preparation. Electron flow was much less sensitive to linolenic acid than $\mathrm{O}_{2}$ evolution was, and a $\mathrm{C}_{18: 3 / \text { chlorophyll molar }}$ ratio of 2.25 was needed for half-inhibition.

Further, the sensitivity to linolenic acid of $\mathrm{CO}_{2}$ fixation and $\mathrm{O}_{2}$ evolution was tested under the same conditions. The results in Table $\mathrm{l}$ indicate that $\mathrm{CO}_{2}$ fixation was more sensitive than $\mathrm{CO}_{2}$-dependent $\mathrm{O}_{2}$ evolution. A 50\% decrease in $\mathrm{CO}_{2}$ fixa- 
Table 1 Comparison of $\mathrm{O}_{2}$ evolution and $\mathrm{CO}_{2}$ fixation by intact chloroplasts in the presence of linolenic acid

\begin{tabular}{cccc}
\hline $\begin{array}{c}\text { Linolenic acid } \\
(\mu \mathrm{M})\end{array}$ & \multicolumn{2}{c}{$\%$ of controls } & $\begin{array}{c}\text { Ratio } \\
\mathrm{O}_{2} / \mathrm{CO}_{2}\end{array}$ \\
\cline { 2 - 4 } & $\mathrm{O}_{2}$ evolution & $\mathrm{CO}_{2}$ fixation & 1 \\
40 & $100^{\circ}$ & $100^{\circ}$ & 1.69 \\
50 & 86 & 51 & 1.88 \\
60 & 80 & 46 & 1.75 \\
80 & 72 & 41 & 1.85
\end{tabular}

a The controls $(100 \%)$ were 30 and $31 \mu$ moles $\cdot \mathrm{mg} \mathrm{chl}^{-1} \cdot \mathrm{hr}^{-1}$ for $\mathrm{CO}_{2}$-dependent $\mathrm{O}_{2}$ evolution and $\mathrm{CO}_{2}$ fixation, respectively.

tion was observed for a $\mathrm{C}_{18: 3} /$ chlorophyll molar ratio of 0.36 . This may be compared to the values of 0.7 and 2.25 for the corresponding inhibitions of $\mathrm{O}_{2}$ evolution and photoreduction of $\mathrm{NADP}^{+}$, respectively. Moreover, for each concentration of $\mathrm{C}_{18: 3}$, the ratio of $\mathrm{CO}_{2}$ fixation to $\mathrm{O}_{2}$ evolution remained constant at 0.5 to 0.6 . Thus, on a concentration basis, $\mathrm{C}_{18: 3}$ inhibited $\mathrm{CO}_{2}$ fixation the most, $\mathrm{O}_{2}$ evolution less and photoreduction of $\mathrm{NADP}^{+}$the least.

These results suggest that the inhibition of $\mathrm{CO}_{2}$ fixation and of $\mathrm{CO}_{2}$-dependent $\mathrm{O}_{2}$ evolution by linolenic acid is not due to an inhibition of the photochemical reactions but is caused by an impairment of other factors such as the enzymatic steps in the Calvin-Benson cycle or the permeability to reactants of the chloroplast envelope. Experiments with crude extracts from chloroplasts have shown, however, that linolenic acid has no effect on six key enzymes of the Calvin-Benson cycle (25): ribulose 5-P-isomerase, ribulose 5-P-kinase, ribulose 1,5-bisP-carboxylase, 3-phosphoglycerate-kinase, glyceraldehyde 3-phosphate dehydrogenase and phosphotriose-isomerase. Similar results were also reported by Pedersen et al. (29) using shorter chain fatty acids.

In order to test the second hypothesis that permeability of the envelope to reactants is affected by linolenate, we investigated the action of $\mathrm{C}_{18: 3}$ on pyrophosphatedependent oxygen evolution by intact chloroplasts. This activity is an indirect estimation of $\mathrm{Pi}$ uptake by intact chloroplasts according to Schwenn et al. (32). They have demonstrated that pyrophosphate, together with pyrophosphatase from broken chloroplasts, maintain the external $\mathrm{Pi}$ at or near a concentration optimal for photosynthesis, and that phosphate concentration governs the rate of synthesis and

Table 2 Infuence of linolenate on inorganic alkaline pyrophosphatase

\begin{tabular}{|c|c|c|c|c|}
\hline \multirow{2}{*}{ Additions } & \multirow{2}{*}{$\begin{array}{l}\text { Ratio } \mathrm{mM} \\
\mathrm{Mg}^{2+} / \mathrm{PPi}\end{array}$} & \multicolumn{3}{|c|}{$\begin{array}{c}\mu \text { moles } \mathrm{Pi} \text { released } / \mathrm{mg} \mathrm{chl} / 10 \mathrm{~min} \text { as a function } \\
\text { of linolenate concentration }(\mu \mathrm{M})\end{array}$} \\
\hline & & 0 & 100 & 300 \\
\hline $4 \mathrm{mM} \mathrm{MgCl} 2$ & 2 & 1.47 & 1.52 & 1.43 \\
\hline $8 \mathrm{~mm} \mathrm{MgCl}_{2}$ & 4 & 1.36 & 1.36 & 1.31 \\
\hline
\end{tabular}

The reaction mixture contained $100 \mathrm{~mm}$ Tricine ( $\mathrm{pH} 8.6$ ), $2 \mathrm{mM}$ pyrophosphate tetrasodium ( $\mathrm{pH} 8.6$ ), $\mathrm{MgCl}_{2}$ as indicated and $0.1 \mathrm{ml}$ enzyme extract corresponding to an original chloroplast suspension containing $100 \mu \mathrm{g}$ chlorophyll $/ \mathrm{ml}$. Reaction time: $10 \mathrm{~min}$ at $25^{\circ} \mathrm{C}$. 
export of photosynthetic intermediates. Fig. 2A shows that in the absence of linolenic acid, $\mathrm{O}_{2}$ evolution increased with increasing PPi concentration up to $4 \mathrm{mM}$. In the absence of $\mathrm{PPi}$ an increase in linolenic acid concentration decreased the activity. Addition of PPi reversed the inhibition due to low $\mathrm{Pi}$ levels in a manner which depended on the concentration of linolenic acid. In the presence of 20,40 and $60 \mu \mathrm{M}$ linolenic acid, maximum activity was obtained with $1.5,4$ and $8 \mathrm{mM} \mathrm{PPi}$, respectively. Fig. 2B shows clearly that the inhibition of the PPi-dependent $\mathrm{O}_{2}$ evolution by linolenic acid was more significant than that of the $\mathrm{O}_{2}$ evolution not dependent on PPi. The stimulatory effect of PPi at low concentrations is effectively inhibited by linolenate. A very low concentration of $\mathrm{PPi}$, however, was sufficient to reverse the effect of $20 \mu \mathrm{M} \mathrm{C}_{18: 3}$ while the effects of 40 and $60 \mu \mathrm{M} \mathrm{C}_{18: 3}$ were progressivley less easily reversed by PPi. Linolenate (particularly at $20 \mu \mathrm{M}$ ) increased the final level of $\mathrm{O}_{2}$ evolution. Since $\mathrm{O}_{2}$ evolution is an indirect estimation of pohsphate uptake under these conditions (32), it may be deduced that $\mathrm{C}_{18: 3}$ should inhibit both $\mathrm{O}_{2}$ evolution and $\mathrm{Pi}$ uptake. Necessary criteria for this deduction are that pyrophosphate does not permeate the intact spinach chloroplast, as is known to

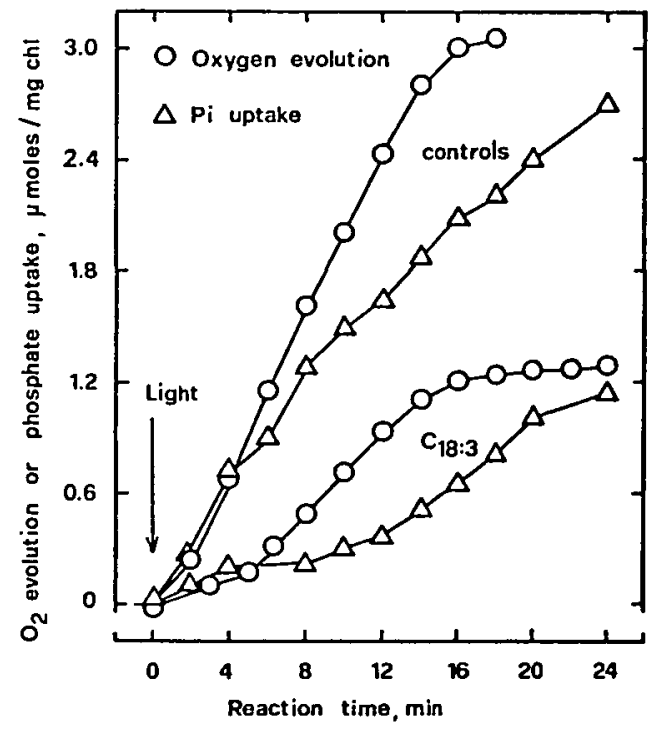

Fig. 3.

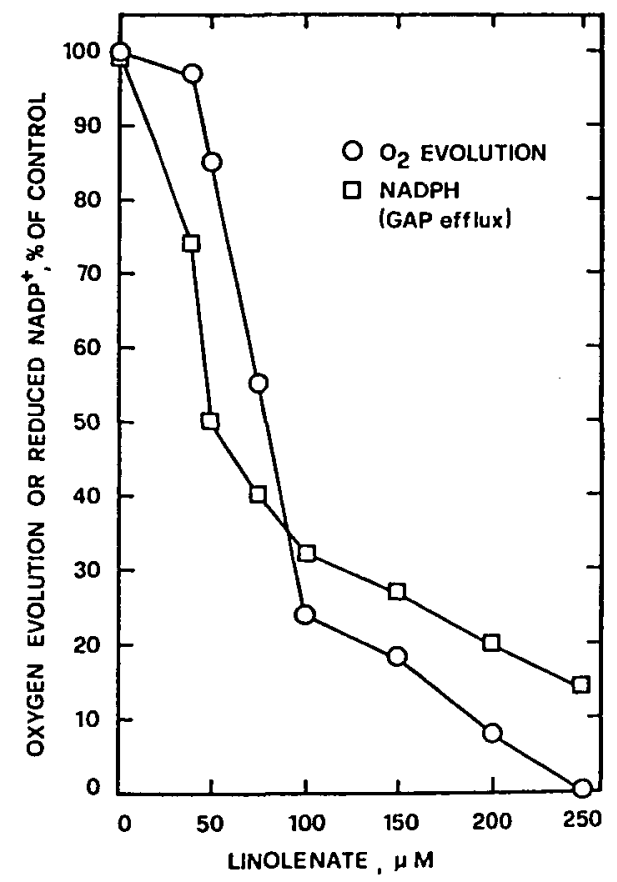

Fig. 4.

Fig. 3. Effect of linolenate $(80 \mu \mathrm{M})$ on $\mathrm{CO}_{2}$-dependent $\mathrm{O}_{3}$ evolution and on phosphate uptake by intact chloroplasts. Fig. 4. Effect of linolenate on D-glyceraldehyde 3-P (GAP) effux and $\mathrm{CO}_{2}$-dependent $\mathrm{O}_{2}$ evolution in intact chloroplasts. The reaction mixture contained $350 \mathrm{~mm}$ sorbitol, $50 \mathrm{~mm}$ HEPES-NaOH $(\mathrm{pH} 8), 0.2 \mathrm{~mm} \mathrm{Na}-$ isoascorbate, $6 \mathrm{~mm} \mathrm{KHCO}_{3}, 1 \mathrm{~mm} \mathrm{Na}_{4} \mathrm{P}_{2} \mathrm{O}_{7} \cdot 10 \mathrm{H}_{2} \mathrm{O}\left(\mathrm{pH}\right.$ 8), $0.5 \mathrm{~mm} \mathrm{~K} \mathrm{~K}_{2} \mathrm{HPO}_{4}, 2 \mathrm{~mm}$ EDTA, $1 \mathrm{~mm}$ $\mathrm{MnCl}_{2}, 1 \mathrm{~mm} \mathrm{MgCl}, 1 \mathrm{~mm} 3-\mathrm{PGA}, 0.2 \mathrm{~mm} \mathrm{NADP}^{+}, 10^{-4}$ to $10^{-2} \mathrm{EU} / \mathrm{ml}$ of non reversible D-glyceraldehyde-3-phosphate dehydrogenase (NR-DGAPDH) and intact chloroplasts (50 $\mu \mathrm{g}$ chlorophyll/ml). The concentration of ethanol was $0.3 \%$ in all reaction mixtures. The control rates $(100 \%)$ were 5 $\mu$ moles NADPH formed $/ \mathrm{mg} \mathrm{chl} / \mathrm{hr}$ and $33 \mu$ moles $\mathrm{O}_{2}$ evolved $/ \mathrm{mg} \mathrm{chl} / \mathrm{hr}$. 
be the case (32), and that the hydrolysis of pyrophosphate is neither activated nor inhibited by $\mathrm{C}_{18: 3}$, as shown in Table 2 .

Fig. 3 shows a direct measurement of the effect of linolenic acid on $\mathrm{CO}_{2}$-dependent $\mathrm{O}_{2}$ evolution and $\mathrm{Pi}$ uptake as a function of time, both activities being measured simultaneously in the same vessel. Since no ADP was added, photophosphorylation by broken chloroplasts could not occur and the fall in $\mathrm{Pi}$ concentration is the result of $\mathrm{Pi}$ uptake by the intact chloroplasts. In the presence of $0.7 \mathrm{mM} \mathrm{Pi}$, the rate of $\mathrm{O}_{2}$ evolution by the untreated chloroplasts was less than in the standard medium containing $4 \mathrm{~mm} P P i$ (legend to Fig. 1). This is in agreement with the data reported by Lilley et al. (23). In the controls, the rate of $\mathrm{Pi}$ uptake was less than that of $\mathrm{O}_{2}$ evolution. Both activities were inhibited by $\mathrm{C}_{18: 3}$ to almost the same extent. It is well established that the absorption of orthophosphate by intact chloroplasts is accompanied by the export of phosphorylated compounds of the Calvin-Benson cycle $(14,15)$. Since linolenate inhibited the uptake of orthophosphate (Fig. 3), it is to be expected that linolenate also inhibits the efflux of these photosynthetic intermediates. Using cytoplasmic NR-GAPDH, Kelly and Gibbs (18) pointed out that the 3-PGA/GAP shuttle is a good simulation of the transport of phosphorylated compounds between the chloroplast and the cytoplasm. Fig. 4 shows that increasing concentrations of linolenate simultaneously decreased $\mathrm{O}_{2}$ evolution and GAP efflux. One cannot exclude the possibility, however, that linolenate might also inhibit the influx of exogenous 3-PGA (the function of which is to initiate the shuttle). Nevertheless, in both cases the inhibition would occur at the "phosphate translocator" site.

\section{Discussion}

In addition to the inhibitory effects of unsaturated free fatty acids on the photochemical reactions in thylakoid membranes $(8,26,27,34-37,39,41)$, we have found that linolenate inhibits photosynthesis by intact chloroplasts. This inhibition was due neither to a lack of NADPH in the chloroplasts nor to a direct inhibition of the enzyme activities of the Calvin-Benson cycle. Indeed, linolenate inhibited $\mathrm{CO}_{2}$ fixation and oxygen evolution much more effectively than electron transport (Fig. 1 and Table 1). Moreover, in agreement with Pedersen et al. (29), we observed that fatty acids did not inhibit six key enzymatic activities of the Calvin-Benson cycle (ref. 25, cf. also Results). Thus, the inhibition of photosynthesis by linolenate is related to the integrity of the chloroplast envelope.

The principal movement of metabolites across the envelope involves influx of $\mathrm{Pi}$ and $\mathrm{CO}_{2}$ and a corresponding efflux of certain sugar-phosphates and especially triosephosphates (15). This transport is mediated by a translocator which is located in the inner membrane of the envelope (15). The polypeptide nature of this translocator has been characterized recently (12). Our results suggest that linolenate disturbs the function of the translocator. We have demonstrated here that linolenate inhibited $\mathrm{CO}_{2}$-dependent $\mathrm{O}_{2}$ evolution, phosphate uptake and the efflux of at least one of the phosphorylated compounds, 3-phosphoglyceraldehyde (Fig. 3 and 4). These results suggest that the inhibition of photosynthesis by linolenate is due in the first instance to an inhibition of the phosphate-metabolite exchange across the envelope which in turn causes an accumulation of photosynthetic phosphorylated inter- 
mediates in the stroma. Such an accumulation would inhibit by feedback effects several of the key enzymes of the Calvin-Benson cycle $(1,5,28)$. Under these conditions an inhibition of carboxylation has been observed (Table 1). Since electron transport in broken chloroplasts was not affected by low concentrations of linolenate (Fig. 1), it is likely to be the increased ratio NADPH/NADP+ which inhibits electron transport according to the mechanism demonstrated by Arnon and Chain (2). This whole sequence of events leading to the increased $\mathrm{NADPH} / \mathrm{NADP}+$ ratio could explain why $\mathrm{CO}_{2}$ fixation is more effectively inhibited than $\mathrm{O}_{2}$ evolution (Table l). Moreover, the addition of compounds which affect the exchange of metabolites across the envelope increases the molar ratio of $\mathrm{O}_{2}$ evolved and $\mathrm{CO}_{2}$ fixed above unity. For instance, the addition of 3-PGA $(1,28)$ and high concentrations of orthophosphate $(7,28)$ inhibited $\mathrm{CO}_{2}$ fixation more significantly than $\mathrm{O}_{2}$ evolution. The observation that linolenate has the same effect (Table 1) gives further evidence that $\mathrm{C}_{18: 3}$ may act on metabolite transport across the envelope.

Recently Purczeld et al. (31) have demonstrated that an addition of octanoate $(10-20 \mathrm{~mm})$ to intact chloroplasts lowers the stroma $\mathrm{pH}$ in the light, resulting in a diminution of the hydrolysis of fructose and sedoheptulose bisphosphates, and in a subsequent inhibition of $\mathrm{CO}_{2}$-dependent $\mathrm{O}_{2}$ evolution. The inhibition of $\mathrm{CO}_{2}$ fixation by linolenate could therefore also be interpreted as due to an alteration of the proton gradient across the envelope and a lowering of the stroma $\mathrm{pH}$. If the very low concentration of linolenate used in our experiments can effectively induce a drop in the $\mathrm{pH}$ of the stroma, such a decrease in $\mathrm{pH}$ might also alter the function of the "translocator" indirectly. Indeed, preliminary experiments (results to be published) have shown that Pi uptake inhibitited by linolenate was restored at alkaline $\mathrm{pH}$.

It is concluded that linolenate inhibits photosynthesis by impairing the exchange of metabolites across the chloroplast envelope either by direct action on the "phosphate translocator" or by a decrease in the stroma $\mathrm{pH}$.

We would like to thank Dr. G. J. Kelly for introducing us to his shuttle technique and for many helpful discussions, Dr. R. H. Marchant for his critical reading of the manuscript and Mrs J. Smutny for her technical help. This research was supported by the Swiss National Science Foundation (Grants No. 3.2470.74 and 3.119.77 to P.A.S.).

\section{References}

( 1 ) Andersen, W. R. and M. Gibbs: Inhibition of $\mathrm{CO}_{2}$ fixation in intact spinach chloroplasts by 3-phosphoglyceric acid. Biochem. Biophys. Res. Commun. 62: 953-956 (1975).

(2) Arnon, D. I. and R. K. Chain: Regulation of ferredoxin-catalyzed photosynthetic phosphorylation. Proc. Nal. Acad. Sci. U.S. 72: 4961-4965 (1975).

(3) Bruinsma, J.: A comment on the spectrophotometric determination of chlorophyll. Biochim. Biophys. Acta 53: 576-578 (1961).

(4) Buchanan, B. B. and D. I. Arnon: Ferredoxins from photosynthetic bacteria, algae and higher plants. In Methods in Enzymology. Edited by A. San Pietro. Vol. 23, p. 413-440. Academic Press, New York and London, 1971.

(5) Buchanan, B. B. and P. Schürmann: Regulation of ribulose 1,5-diphosphate carboxylase in the photosynthetic assimilation of carbon dioxide. J. Biol. Chem. 248: 4956-4964 (1973).

(6) Chen, P.S., T. Y. Toribara and H. Warner: Assay of inorganic phosphate, total phosphate and phosphatases. Anal. Chem. 28: 1756-1758 (1956). 
(7) Cockburn, W., D. A. Walker and C. W. Baldry: Photosynthesis by isolated chloroplasts. Reversal or orthophosphate inhibition by Calvin-cycle intermediates. Biochem. J. 107: 89-95 (1968).

( 8 ) Constantopoulos, G. and C. N. Kenyon: Release of free fatty acids and loss of Hill activity by aging spinach chloroplasts. Plant Physiol. 43: 531-536 (1968).

(9) Davies, J. W. and E. C. Cocking: Liquid scintillation counting of ${ }^{14} \mathrm{C}$ and ${ }^{3} \mathrm{H}$ samples using glass-fibre. Biochim. Biophys. Acta 115:511-513 (1966).

(10) Douce, R. and C. Lance: Altération des activités oxydatives et phosphorylantes des mitochondries de chou-fleur sous l'action de phospholipases et du vieillissement. Physiol. vég. 10: 181198 (1972).

(11) Fiske, C. H. and Y. Subbarow: The colorimetric determination of pohosphorus. J. Biol. Chem. 66: 375-400 (1925).

(12) Fligge, V. I. and H. W. Heldt: Identification of a protein involved in phosphate transport of chloroplasts. FEBS Lett. 68: 259-262 (1976).

(13) Heber, U. and K. A. Santarius: Direct and indirect transfer of ATP and ADP across the chloroplast envelope. Z. Naturforsch. 25b: 718-728 (1970).

(14) Heldt, H. W. and L. Rapley: Specific transport of inorganic phosphate, 3-phosphoglycerate and dihydroxyacetonephosphate and of dicarboxylates across the inner membrane of spinach chloroplasts. FEBS Lett. 10: 143-148 (1970).

(15) Heldt, H. W.: Metabolite transport in intact spinach chloroplasts. In The Intact Chloroplasts. Edited by J. Barber. p. 215-234. Elsevier/North-Holland, Biomedical Press, chapt. 6 (1976).

(16) Hoshina, S., T. Kaji and K. Nishida: Photoswelling and light-inactivation of isolated chloroplasts I. Change in lipid content in light-aged chloroplasts. Plant \& Cell Physiol. 16: 465-474 (1975).

(17) Kalberer, P. P., B. B. Buchanan and D. I. Arnon: Rates of photosynthesis by isolated chloroplasts. Proc. Nat. Acad. Sci. 57: 1542-1549 (1967).

(18) Kelly, G. J. and M. Gibbs: Nonreversible D-glyceraldehyde 3-phosphate dehydrogenase of plant tissues. Plant Physiol. 52:111-118 (1973).

(19) Kelly, G. J. and M. Gibbs: A mechanism for the indirect transfer of photosynthetically reduced nicotinamide adenine dinucleotide phosphate from chloroplasts to the cytoplasm. ibid. 52: 674-676 (1973).

(20) Losada, M., A. V. Trebst and D. I. Arnon: Photosynthesis by isolated chloroplasts XI. $\mathrm{CO}_{2}$ assimilation in a reconstituted chloroplast system. J. Biol. Chem. 235: 832-839 (1960).

(21) Mackender, R. O. and R. M. Leech:. The galactolipid, phospholipid, and fatty acid composition of the chloroplast envelope membranes of Vicia faba L. Plant Physiol. 53 : 496-502 (1974).

(22) McCarty, R. E. and A. T. Jagendorf: Chloroplast damage due to enzymatic hydrolysis of endogenous lipids. ibid. 40: 725-735 (1965).

(23) McLilley, R. C., J. D. Schwenn and D. A. Walker: Inorganic pyrophosphatase and photosynthesis by isolated chloroplasts II. The controlling influence of orthophosphate. Biochim. Biophys. Acta 325: 596-604 (1973).

(24) McSwain, B. D. and D. I. Arnon: Enhancement effects and the identity of the two photochemical reactions of photosynthesis. Proc. Nat. Acad. Sci. U.S. 61: 989-996 (1968).

(25) Mvé Akamba, L. and P. A. Siegenthaler: Influence of linolenic acid on photosynthesis in intact spinach chloroplasts. (U.K. Science Committee) 4th Intern. Congress on Photosynthesis, Reading, U.K., Abstract p. 265. 1977.

(26) Okamoto, T. and S. Katoh: Linolenic acid binding by chloroplasts. Plant $\mathcal{E}$ Cell Physiol. 18: 539-550 (1977).

(27) Okamoto, T., S. Katoh and S. Murakami: Effects of linolenic acid on spinach chloroplast structure. ibid. 18: 551-560 (1977).

(28) Paulsen, J. M. and M. D. Lane: Spinach ribulose diphosphate carboxylase I. Purification and properties of the enzyme. Biochem. 5: 2350-2357 (1966).

(29) Pedersen, T. A., M. Kirk and J. A. Bassham: Inhibition of photophosphorylation and photosynthetic carbon cycle reaction by fatty acids and esters. Biochim. Biophys. Acta 112: 189-203 (1966). 
(30) Phillips, G. B., J. T. Dodge and C. Howe: The effect of aging of human red cells in vivo on their fatty acid composition. Lipids 4: 544-549 (1969).

(31) Purczeld, P., C. J. Chon, A. R. Portis, H. W. Heldt and U. Heber: The mechanism of the control of carbon fixation by the $\mathrm{pH}$ in the chloroplast stroma. Studies with nitrite-mediated proton transfer across the envelope. Biochim. Biophys. Acta 501 : 488-498 (1978).

(32) Schwenn, J. D., R. C. McLilley and D. A. Walker: Inorganic pyrophosphatase and photosynthesis by isolated chloroplasts I. Characterization of chloroplast pyrophosphatase and its relation to the response to exogenous pyrophosphate. ibid. 325: 586-595 (1973).

(33) Siegenthaler, P. A.: Vieillissement de l'appareil photosynthétique II. Effet synergique de la lumière et du vieillissement in vitro sur les activités photochimiques de chloroplastes isolés d'epinard. Plant \& Cell Physiol. 10: 811-820 (1969).

(34) Siegenthaler, P. A.: Aging of the photosynthetic apparatus IV. Similarity between the effects of aging and unsaturated fatty acids on isolated spinach chloroplasts as expressed by volume changes. Biochim. Biophys. Acta 275: 182-191 (1972).

(35) Siegenthaler, P. A.: Change in $\mathrm{pH}$ dependence and sequential inhibition of photosynthetic activity in chloroplasts by unsaturated fatty acids. ibid. 305: 153-162 (1973).

(36) Siegenthaler, P. A. and J. Horakova: Control of the photosynthetic electron transport by free fatty acids and $\mathrm{Mn}^{2+}$ salts. Proc. Third Intern. Congress on Photosynthesis, Rehovot, Israel, Edited by M. Avron. p. 655-664, vol. I. Elsevier Sci. Publ. Co., Amsterdam 1974.

(37) Siegenthaler, P. A. and F. Depéry: Influence of unsaturated fatty acids in chloroplasts. Shift of the $\mathrm{pH}$ optimum of electron flow and relations to $\triangle \mathrm{pH}$, thylakoid internal $\mathrm{pH}$ and proton uptake. Eur. J. Biochem. 61: 573-580 (1976).

(38) Siegenthaler, P. A. and F. Depéry: Aging of the photosynthetic apparatus VI. Changes in pH dependence of $\triangle \mathrm{pH}$, thylakoid internal $\mathrm{pH}$ and proton uptake and relationships to electron transport. Plant \& Cell Physiol. 18: 1047-1055 (1977).

(39) Siegenthaler, P. A. and A. Rawlyer: Aging of the photosynthetic apparatus V. Change in pH dependence of electron transport and relationships to endogenous free fatty acids. Plant Sci. Lett. 9: 265-273 (1977).

(40) Walker, D. A. and R. Hill: The relation of oxygen evolution to carbon assimilation with isolated chloroplasts. Biochim. Biophys. Acta 131 : 330-338 (1967).

(41) Wintermans, J. F. G. M., P. J. Helmsing, B. J. J. Polman, J. van Gisbergen and J. Collard: Galactolipid transformations and photochemical activities of spinach chloroplasts. ibid. 189: 95-105 (1969). 